\title{
DYANMIC ANALYSIS OF SHAPE MEMORY ALLOY OSCILLATORS IN ACTIVE SUSPENSION SYSTEM
}

\author{
Rusul Saad Ahmed ${ }^{1}$ \\ rusul1988.mkh@gmail.com
}

Qasim Abaas Atiyah ${ }^{2}$

20044@uotechnology.edu.iq

\author{
Imad Abdlhussein Abdulsahib \\ 20018@uotechnology.edu.iq
}

1,2, 3 Mechanical Engineering Department University of Technology Baghdad, Iraq

\section{ABSTRACT}

Smart materials have a growing technological importance due to their unique thermomechanical characteristics. Shape memory alloys belong to this class of materials being easy to manufacture, relatively lightweight, and able to produce high forces or displacements with low power consumption. These aspects could be exploited in different applications including vibration control. A dynamic vibration absorber (DVA) can be used as an effective vibration control device. It is essentially a secondary mass, attached to an original system via a spring and damper. The natural frequency of the DVA is tuned such that it coincides with the frequency of unwanted vibration in the original system. This work aims to develop a dynamic vibration absorber with the help of shape memory alloy (SMA) springs in order to attenuate the vibration for a range of excitation frequencies. The experimental apparatus consisted of low-friction cars free to move in a rail. A shaker that provides harmonic forcing excites the system. Special attention is dedicated to the analysis of vibration reduction that can be achieved by considering different approaches exploiting temperature variations promoted either by electric current changes or by vibration absorber techniques. The results established that adaptability due to temperature variations is defined by modulus of stiffness.

Keywords: Shape memory alloy (SMA), Control, Natural frequency, Dynamic vibration absorber.

\section{التحليل الايناميكي لمذبذبات سبائك ذاكرة الشكل في نظام التعليق النشط \\ عماد عبدالحسين عبدالصاحب \\ قاسم عباس عطية \\ رسل سعد أحمد}

الخلاصة

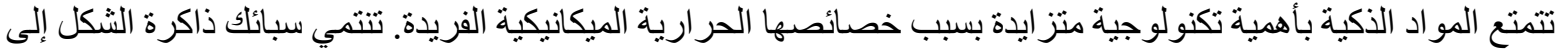

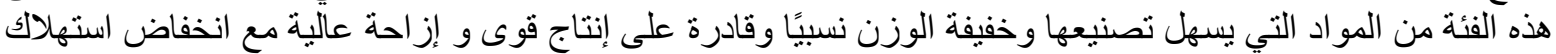

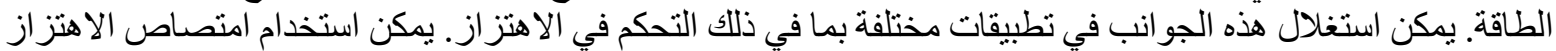

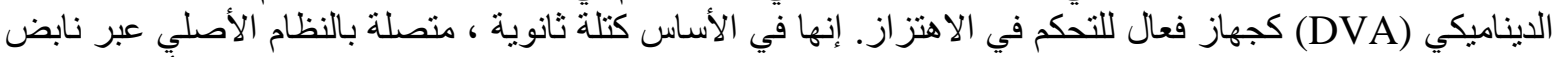

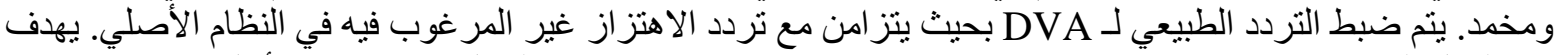

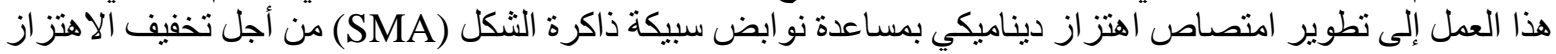

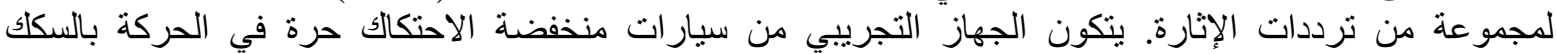

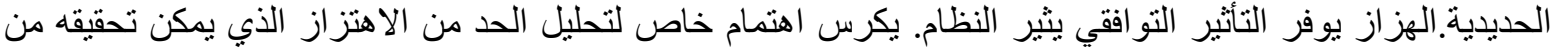

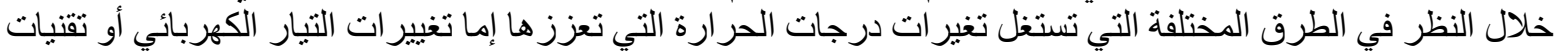

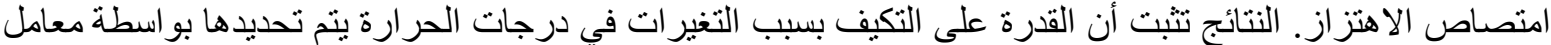




NOMENCLTURE
Latin Symbols
$\mathbf{A}_{f}$
$\mathbf{A}_{s}$
$\boldsymbol{k}$
$\mathrm{M}_{\boldsymbol{s}}$
$\mathrm{M}_{s}$
$\mathrm{M}_{f}$

\section{Description}

the austenitic finish temperature is $45^{\circ} \mathrm{C}$ (at heating when the Nitinol finishes the transformation to austenite). the austenitic starts temperature is $37^{\circ} \mathrm{C}$ (at heating when the Nitinol begins the transformation to austenite). the modulus of stiffness $(\mathrm{N} / \mathrm{mm})$ mass of car $(\mathrm{kg})$ the martensitic starts temperature is $28^{\circ} \mathrm{C}$ (at cooling when the Nitinol begins the transformation to martensite).

the martensitic finishes temperature is $17^{\circ} \mathrm{C}$ (at cooling when the Nitinol finishes the transformation to martensite).

\section{INTRODUCTION}

Vibration damping is one of the manifestations of the dissipation of mechanical energy related to the motion in mechanical systems. Damping processes have been studied for a long time. The development of research on problems related to the vibration entails studying its damping. Admittedly, those studies lag behind other aspects of the investigation of vibrating motion. Therefore, it happens that the damping forces are small compared to the other interactions present in a mechanical system, yet their mathematical description remains much more complicated. Shape memory alloy is a material that enables a previously memorized shape to be restored, under the influence of a controlled external stimulus. This change results from a thermoelastic phase change caused by the flow of thermal energy. The phenomena occurring in SMA include the one-way and two-way shape memory effects and pseudoelasticity. They are related to the phase change caused by temperature and/or external stress. These unique phenomena enable the use of the alloys in many fields of engineering. They are primarily used as coupling elements, actuators, and as surgical implants, such as staples, bolts, stents, clamps, etc. Because of their properties, SMA is also applied in the vibration reduction systems as active, semi-active or passive elements. As a result, the energy of vibrations is dissipated inside dashpots or transferred to other vibration systems (dynamic vibration absorber). Han et al. (2003). designed a damper device based on a shape memory alloy (SMA). The study showed that vibration decay of the SMA damper controlled frame is much faster than that of the uncontrolled frame. The results depicted that the SMA dampers are very effective in reducing the structural response and have a great potential for use as efficient energy dissipation devices with the advantages of good control of force and no lifetime limits. Sung et al. (2006). reviewed the applications of SMA materials for passive, active and semi-active controls of civil structures. They provided an overview of the characteristics of SMA and studied the effect of the shape memory (SME) and false flexibility; two major characteristics of SMA associated with the thermal or reversible hysterical phase-induced transformation between austenite and martensite. It was found that these unique characteristics enable the use of SMA as triggers, passive energy dispersants and dampers to control the civil structure. Tiseo et al. (2010). presented a novel model of an adaptive tunable dynamic vibration absorber based on the use of SMA wires, it consists of a SMA clamped wire and a concentrated mass placed in its middle. It worked as a tensioned spring whose stiffness was controlled by varying the electrical current through the wire. The result indicated that the change of the material phase from martensite to austenite induced an increase of the Young modulus, and the adopted wire constraint caused an increase of the internal tension as the transformation occurred. The natural frequency of the absorber was adjusted in a wide range to match one of the targeted frequencies. Mani et al. (2010). used a 
dynamic vibration absorber (DVA) as an effective vibration control device. It's basically an accessory block, attached to the original system by spring and damper. The normal frequency of the DVA was adjusted, so that it coincides with the frequency of unwanted vibration in the original system. This leads to inertial energy absorption transfer from the basic structure. A dynamic vibratory absorber for adaptation was developed with the help of SMA springs in order to relieve the vibration for a range of excitation frequencies. The unique property of Young's temperature-based standards actively changes the spring hardness was used to control vibration. Experimental results showed that the dynamic vibration absorption based on SMA is more effective in reducing the vibration amplitude for a wider frequency range. Chavan (2014). studied the dynamic behavior of a composite beam, which is embedded with SMA wires, and by using an electrical current, these wires converted the thermal energy into mechanical. The result showed that the supply of current passing through the number of wire is directly proportional to the temperature rise so when the SMA wires are actuated the stiffness of beam changes proportionally and this leads to a shift in the natural frequency of the beam. At the range of current 0 to $1.5 \mathrm{Amps}$, the natural frequency of the beam is maximum, and after that, it natural frequency decreases due to increase the heat of beam. The damping factor of the composite beam increased at 0 to $1.5 \mathrm{Amp}$ current and then reduced because the stiffness of beam decreased. Elahinia et al. (2015). used a shape memory alloys in the passive tuned vibration absorbers in order to improve the robustness of the tuned vibration absorbers subjected to mass change in the primary system. For robustness analysis, the mass of the primary system is varied by $\pm 30 \%$ of its nominal mass. The simulation results showed that the shape memory alloy in the tuned vibration absorbers is more robust than the equivalent passive tuned vibration absorbers in reducing the peak vibrations in the primary system subjected to change of its mass. Zdraveski et al. (2016). analyzed the mathematical model of a dynamic vibration absorber with a single and multi-degree of freedom mass, and presented the technique for modeling the differential equitation's with state-space form and block diagrams using Matlab Simulink. The results show that when the primary mass vibrates with a frequency close to the natural frequency and it is without tuned mass damper, the relative speed is causing smaller amplitudes of oscillations. When a tuned mass damper is installed, the relative speed is not affecting the response of the primary mass. If relative speed is included, the response of primary mass is smaller than the case without it. Wagner et al. (2017). focused on the deterministic harmonic loads and dealt with the new positions of the tuned mass dampers that are automatically updated. They used a standard tuned vibration absorber as a single degree-of-freedom system, to suppress the troublesome of resonance or to attenuate the vibration of a structure at a particular forcing frequency, and also used the finite element method to discretize the continuous structure. Santos et al. (2018). explored the capabilities of a novel adaptive vibration absorber for the civil engineering structures, based on the temperature modulation of SMA restitution elements. The real time temperature modulation of the SMAs, through Joule effect, enabled to control the elastic modulus of these elements, by inducing thermal martensitic transformations, and allowed for the adaptation of the stiffness of the absorber, in order to be continuously tunable for a wide frequency range. The absorber comprised a suspended mass connected to the main structure by a set of SMA cables, using a system of multiple pulleys to make the control system more compact.In this work, a hybrid (semi active) and active systems will be used to control the system vibrations and study the effect of many sites of spring types and finding the ideal sites that have the effect of resisting vibrations and absorption. 


\section{MATHMETICAL AND NUMERICAL MODEL}

\section{The equations used in the present study}

The equations of motion (1-5) of the system are derived using Newton's second law of motion.

1. Case One: Three masses and four spring

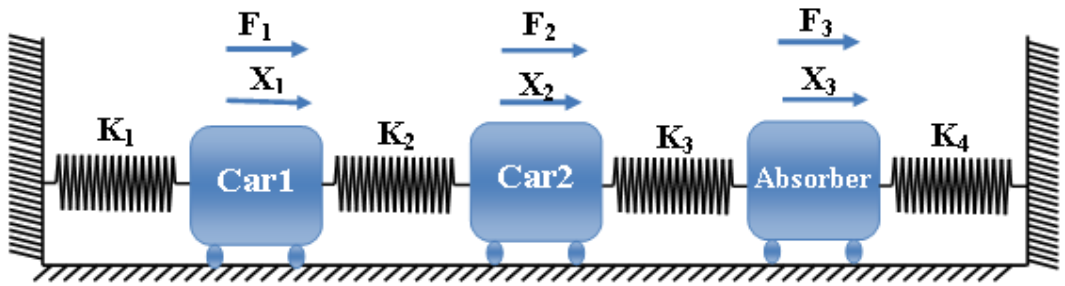

$$
\left|\begin{array}{ccc}
\left(\mathrm{k}_{1}+\mathrm{k}_{2}\right)-\omega^{2} \mathrm{~m}_{1} & -\mathrm{k}_{2} & 0 \\
-\mathrm{k}_{2} & \left(\mathrm{k}_{2}+\mathrm{k}_{3}\right)-\omega^{2} \mathrm{~m}_{2} & -\mathrm{k}_{3} \\
0 & -\mathrm{k}_{3} & \left(\mathrm{k}_{3}+\mathrm{k}_{4}\right)-\omega^{2} \mathrm{~m}_{3}
\end{array}\right|=0
$$

2. Case Two: Three masses and five spring

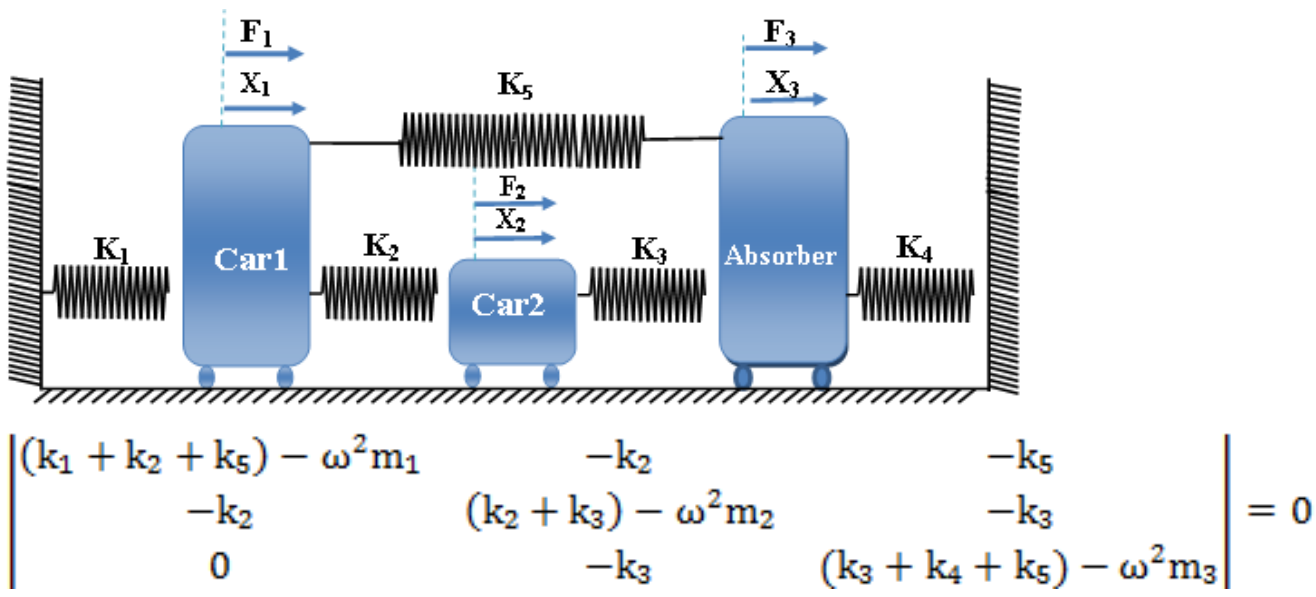

3. Case Three: Therr masses five spring

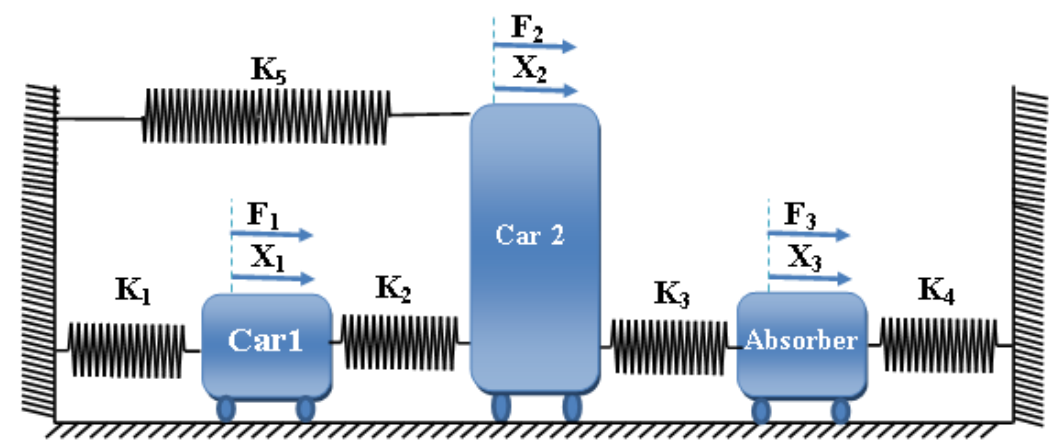

$$
\left|\begin{array}{ccc}
\left(\mathrm{k}_{1}+\mathrm{k}_{2}\right)-\omega^{2} \mathrm{~m}_{1} & -\mathrm{k}_{2} & 0 \\
-\mathrm{k}_{2} & \left(\mathrm{k}_{2}+\mathrm{k}_{3}+\mathrm{k}_{5}\right)-\omega^{2} \mathrm{~m}_{2} & -\mathrm{k}_{3} \\
0 & -\mathrm{k}_{3} & \left(\mathrm{k}_{3}+\mathrm{k}_{4}\right)-\omega^{2} \mathrm{~m}_{3}
\end{array}\right|=0
$$




\section{Case Four: Three masses and six spring}

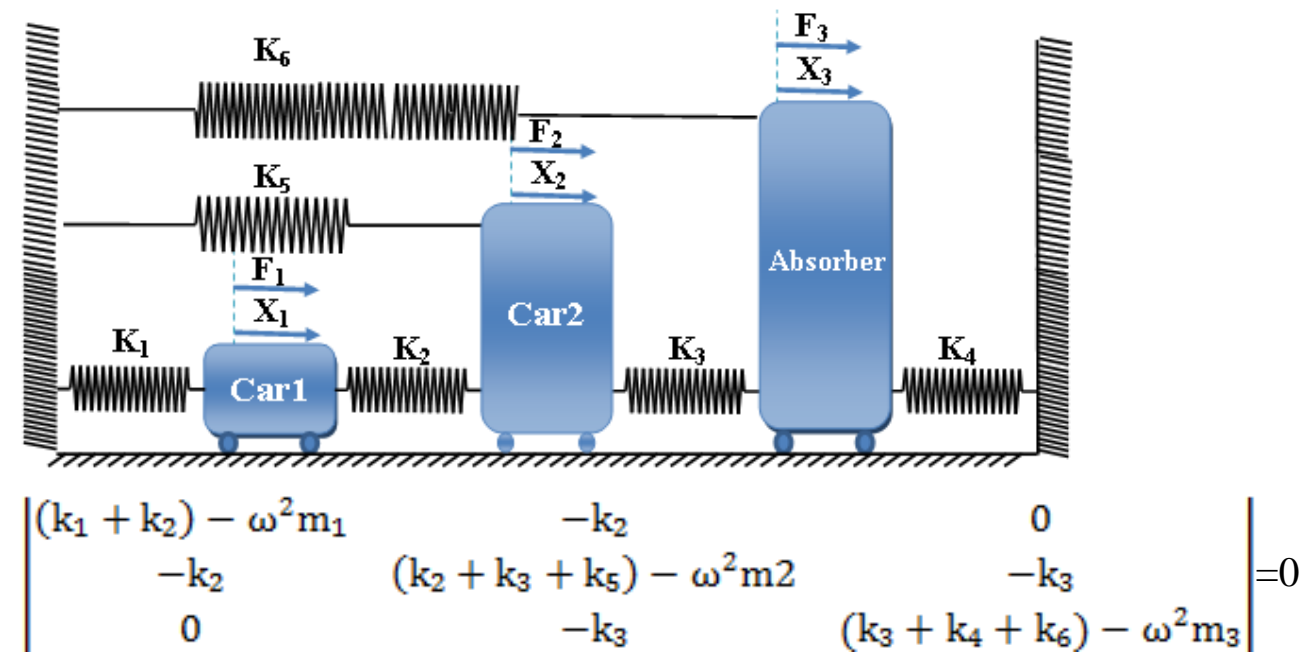

\section{Case Five: Three masses and six spring}

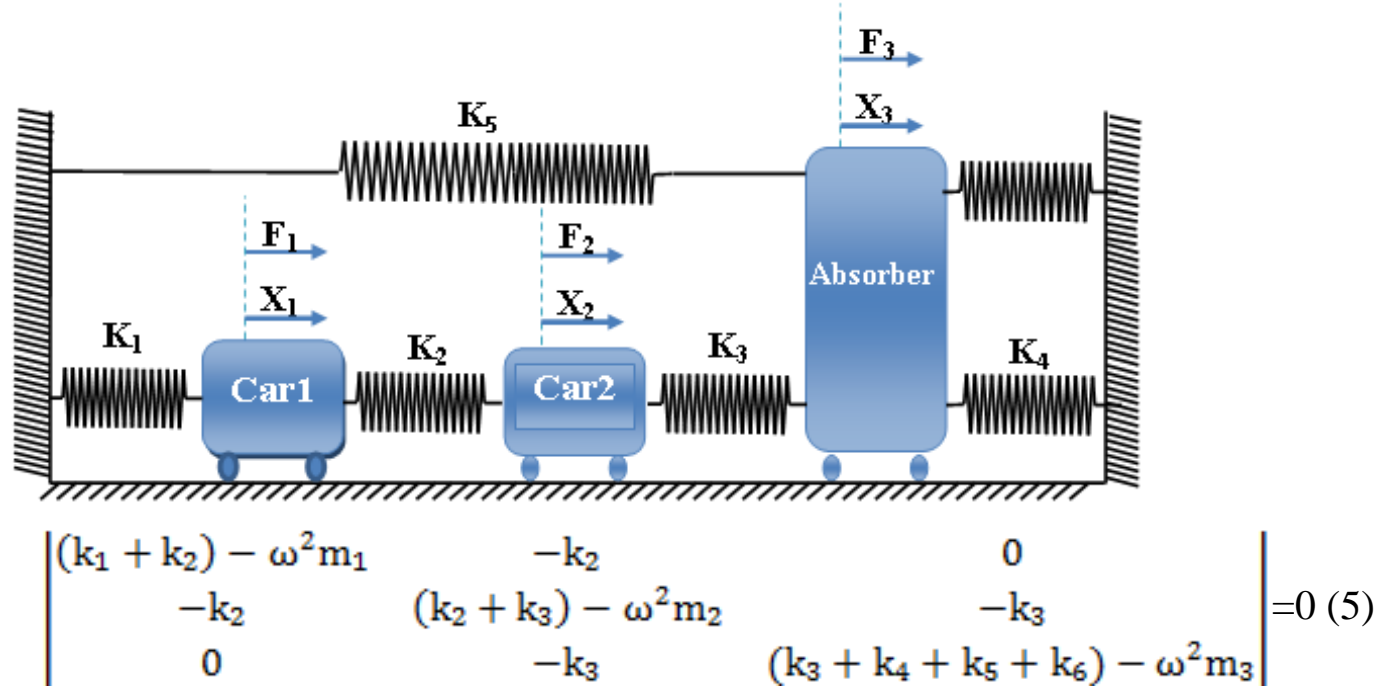

\section{EXPERIMENTAL WORK}

The materials used in the preparation of the device consist of three cars made of acrylic material, and table (1) lists the characteristics of the acrylic material. Four types of steel springs have different lengths and diameters were used, and Table (2) shows the physical properties of the steel springs. A shape memory alloy spring (nitinol), with a perfect combination near 50/50 of nickel and titanium, was utilized. The diameters of the nitinol spring wire are $0.5 \mathrm{~mm}$. Table (3) list the physical properties of nitinol. An experimental test rig was constructed in this work in order to evaluate the effects of the SMA springs on the vibrations of spring-mass system; and how that damped the vibrations. Aluminum rail with length $110 \mathrm{~cm}$ was used, and three cars made from the acrylic material were fixed in the rail with the allowance to remove one of those cars from the rail. One accelerometer was fixed in each car by silicon foam, and many springs made from steel and SMA were connected between these cars. One thermo-cable was fixed on each SMA using silicon foam, both ends for each SMA springs were connected to an electrical current in order to control in the temperature of the SMA spring. Volt-ampere reader was utilized to read the temperatures. The electrical current was controlled by Arduino cart, as shown in figure (1). The steel spring 
constant can be determined using Hooke's law, for the purpose of calculating the values of the spring steel (K) in the laboratory device, as shown in figure (2).

\section{TEST PROCEDURE}

In the experiments, different types of steel springs (lengths and diameters) were used with one type of shape memory alloy springs. The spring position has been changed to obtain the best position to control the system and thus control the vibration. The process of changing the spring location was repeated in different cases of the all the control systems (passive, semiactive and active).

\section{RESULTS AND DISSECTION}

Table (4) shows the variation of the natural frequencies of fourteen cases in 3DOF with the stiffness of first spring $\left(\mathrm{K}_{1}\right)$. In that table, it is observed that when the $\mathrm{K}_{1}$ variation is from $12.0548 \mathrm{~N} / \mathrm{mm}$ to $28.3682 \mathrm{~N} / \mathrm{mm}$, the largest effect on the first natural frequency occurs in case (5). The frequencies increased about $22 \%$. On the other hand, in the same table, the largest effect on the second natural frequency takes place in case (1), the frequencies raised about $10 \%$, and when the effect on the third natural frequency is very little, the frequencies increased around $2 \%$. Table (5) lists the change of the natural frequencies of fourteen cases in $3 \mathrm{DOF}$ with the stiffness of first spring $\left(\mathrm{K}_{2}\right)$. In this table, it is seen that if the $\mathrm{K}_{2}$ change is from $12.0548 \mathrm{~N} / \mathrm{mm}$ to $28.3682 \mathrm{~N} / \mathrm{mm}$, the biggest influence the first natural frequency takes place in case (4). The frequencies raised about $15 \%$. From one hand, in this same table, the biggest influence on the second natural frequency occurs in case (5), the frequencies increased around $30 \%$, and the biggest effect on the third natural frequency takes place in case (1), the frequencies raised about $14 \%$. The variation of the natural frequencies of fourteen cases in 3DOF with the stiffness of third spring $\left(\mathrm{K}_{3}\right)$ is depicted in table (6). In that table, it noticed that when the $\mathrm{K}_{3}$ variation from $12.0548 \mathrm{~N} / \mathrm{mm}$ to $28.3682 \mathrm{~N} / \mathrm{mm}$, the largest effect on the first natural frequency, second natural frequency and third natural frequency occurs in case (2), (1) and (1) respectively. The frequencies increased about 26\%, $19 \%$ and $24 \%$, correspondingly. Table (7) reveals the change of the natural frequencies of fourteen cases in $3 \mathrm{DOF}$ with the stiffness of fourth spring $\left(\mathrm{K}_{4}\right)$. In such table, it is noted that if $\mathrm{K}_{4}$ changed from $12.0548 \mathrm{~N} / \mathrm{mm}$ to $28.3682 \mathrm{~N} / \mathrm{mm}$, the biggest influence on the first natural frequency, second natural frequency and third natural frequency takes place in case (2), (3) and (5), respectively. The frequencies increased around 18\%,11\% and 8\% correspondingly. Table (8) elucidates of the natural frequencies variation of fourteen cases in 3DOF with the stiffness of first spring $\left(\mathrm{K}_{5}\right)$. In the same table, it is seen that when the $\mathrm{K}_{5}$ variation is from $12.0548 \mathrm{~N} / \mathrm{mm}$ to 28.3682 $\mathrm{N} / \mathrm{mm}$, the largest effect on the first natural frequency occurs in case (3). The frequencies increased about $15 \%$. In the other hand, in that table, the biggest influence on the second natural frequency takes place in case (4), the frequencies raised around 3\%, and if the largest effect on the third natural frequency occurs in case (2), the frequencies increased about $20 \%$. The change of the natural frequencies of fourteen cases in 3DOF with the stiffness of third spring $\left(\mathrm{K}_{6}\right)$ is shown in table (9). In that table, it is notice that when the $\mathrm{K}_{6}$ changed from $12.0548 \mathrm{~N} / \mathrm{mm}$ to $28.3682 \mathrm{~N} / \mathrm{mm}$, the biggest influence on the first natural frequency, second natural frequency and third natural frequency occurs in case (5), (4) and (5) respectively. The frequencies increased around $3 \%, 8 \%$ and $8 \%$, correspondingly.

\section{CONCLUSIONS}

1. It was found in three degrees of freedom for passive systems that the greatest impact of the spring site on the natural frequencies is in free systems from one end of it (the first and third masses are connected by spring, and third mass is free from one end). And, when the 
spring $\left(\mathrm{k}_{5}\right)$ is connected and if the third mass is free from one end the largest effect of the spring is between the second mass and third mass $\left(\mathrm{k}_{3}\right)$. Therefore when three masses are connected with four spring, the largest effect of the spring is between the second mass and third mass $\left(\mathrm{k}_{3}\right)$.

2. In hybrid systems, the semi-active control for $3 \mathrm{DOF}$ was found to have the greatest spring effect when the spring was installed between the second mass and the third mass $\left(\mathrm{k}_{3}\right)$.

3. It was found in active systems for $3 \mathrm{DOF}$ when changing the temperature of the springs from $37^{\circ} \mathrm{C}$ to $85^{\circ} \mathrm{C}$, the first natural frequency increased around $22 \%$, while the second natural frequency was about $36 \%$, and the third natural frequency was about $7 \%$.

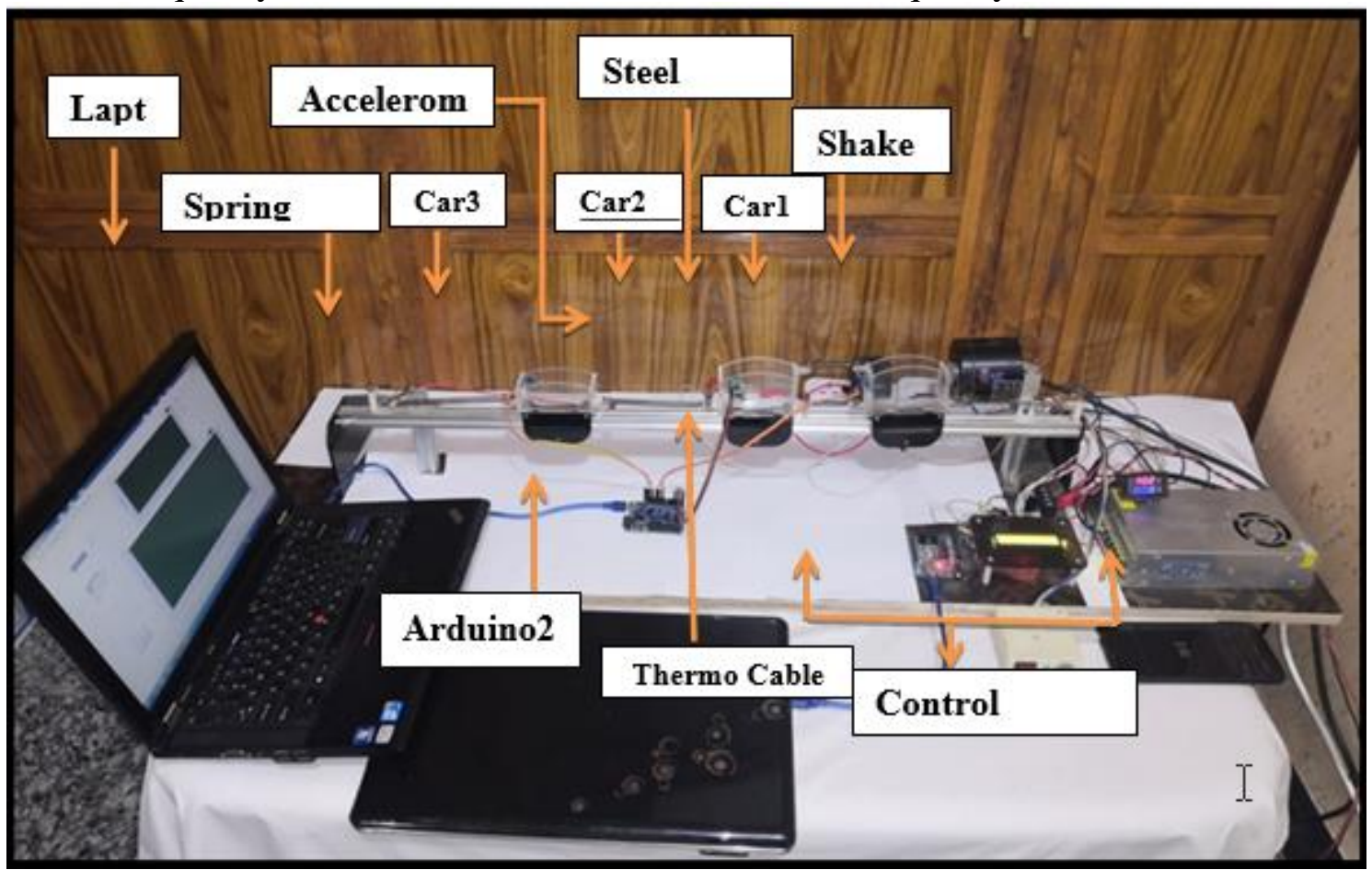

Fig. (1): Photo of the experimental rig.

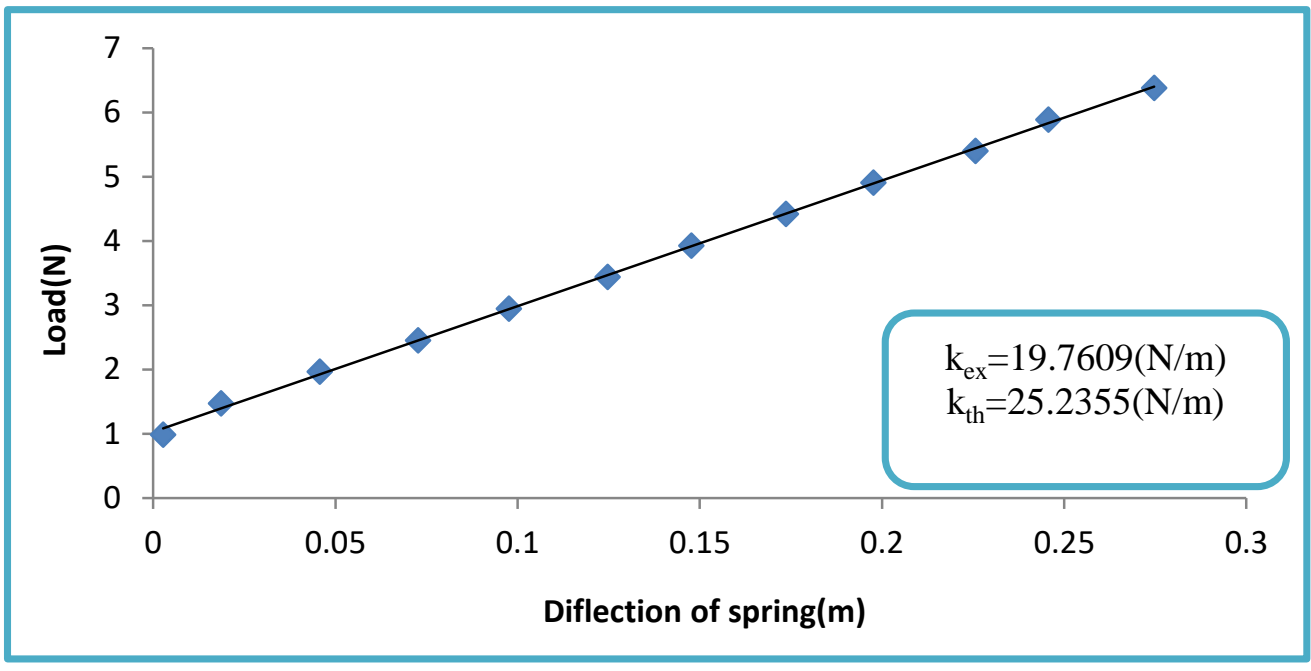

Fig. (2): The steel spring constant. 
Table(1):The properties of acrylic material.

\begin{tabular}{|c|c|}
\hline Properties & Value \\
\hline Tenacity & $2-4.2 \mathrm{~g} / \mathrm{den}$ \\
\hline Density & $1.16 \mathrm{~g} / \mathrm{cm} 3$ \\
\hline Elongation at break & $20-55 \%$ \\
\hline Resiliency & Good \\
\hline Melting point & $230 \circ \mathrm{C}$ \\
\hline Ability to protest friction & Good \\
\hline Properties & Value \\
\hline Tenacity & $2-4.2 \mathrm{~g} / \mathrm{den}$ \\
\hline Density & $1.16 \mathrm{~g} / \mathrm{cm} 3$ \\
\hline Elongation at break & $20-55 \%$ \\
\hline Resiliency & $\mathrm{Good}$ \\
\hline Melting point & $230 \circ \mathrm{C}$ \\
\hline Ability to protest friction & Good \\
\hline
\end{tabular}

Table(2):The properties of steel spring.

\begin{tabular}{|c|c|}
\hline Properties & Value \\
\hline Tensile strength & $685 \mathrm{MPa}$ \\
\hline Yield strength & $525 \mathrm{MPa}$ \\
\hline Bulk modulus & $140 \mathrm{GPa}$ \\
\hline Shear modulus & $80.0 \mathrm{GPa}$ \\
\hline Elastic modulus & $190-210 \mathrm{GPa}$ \\
\hline Poisson's ratio & $0.27-0.30$ \\
\hline Density & $7.85 \mathrm{~g} / \mathrm{cm}^{3}$ \\
\hline Melting point & $1515^{\circ} \mathrm{C}$ \\
\hline
\end{tabular}

Table (3): The properties of SMA spring.

\begin{tabular}{|c|c|}
\hline Properties & Value \\
\hline Modulus of Elasticity & $28 \mathrm{GPa}$ (martensite) \\
& $75 \mathrm{GPa}$ (austenite) \\
\hline Strength & $68.95 \mathrm{MPa}$ (martensite) \\
\hline Elastic modulus & $241.3 \mathrm{MPa}$ (austenite) \\
\hline Poisson's ratio & $190-210 \mathrm{GPa}$ \\
\hline Density & 0.33 \\
\hline Melting point & $6450 \mathrm{~kg} / \mathrm{m}^{3}$ \\
\hline $\mathrm{As}_{\mathrm{f}}$ & $1240-1310^{\circ} \mathrm{C}$ \\
\hline $\mathrm{A}_{\mathrm{f}}$ & $37^{\circ} \mathrm{C}$ \\
\hline & $45^{\circ} \mathrm{C}$ \\
\hline
\end{tabular}


Table (4): The relation between the variations of natural frequencies with the stiffness of first steel spring (K1) in different cases.

\begin{tabular}{|c|c|c|c|c|c|c|c|c|c|}
\hline \multirow{2}{*}{$\begin{array}{c}\text { No of } \\
\text { Case }\end{array}$} & \multicolumn{3}{|c|}{ First natural frequency } & \multicolumn{3}{c|}{ Second natural frequency } & \multicolumn{3}{c|}{ Third natural frequency } \\
\cline { 2 - 11 } & $\begin{array}{c}\mathbf{k}_{\mathbf{1}}= \\
\mathbf{1 2 . 0 5 4 8}\end{array}$ & $\begin{array}{c}\mathbf{k}_{\mathbf{1}}= \\
\mathbf{1 9 . 7 6 0 9}\end{array}$ & $\begin{array}{c}\mathbf{2 8 . 3 6 8 2} \\
\mathbf{2 8 . 3 6}\end{array}$ & $\begin{array}{c}\mathbf{k}_{\mathbf{1}}= \\
\mathbf{1 2 . 0 5 4 8}\end{array}$ & $\begin{array}{c}\mathbf{k}_{\mathbf{1}}= \\
\mathbf{1 9 . 7 6 0 9}\end{array}$ & $\begin{array}{c}\mathbf{k}_{\mathbf{1}}= \\
\mathbf{2 8 . 3 6 8 2}\end{array}$ & $\begin{array}{c}\mathbf{k}_{\mathbf{1}}= \\
\mathbf{1 2 . 0 5 4 8}\end{array}$ & $\begin{array}{c}\mathbf{k}_{\mathbf{1}}= \\
\mathbf{1 9 . 7 6 0 9}\end{array}$ & $\begin{array}{c}\mathbf{k}_{\mathbf{1}}= \\
\mathbf{2 8 . 3 6 8 2}\end{array}$ \\
\hline First & 5.2000 & 5.8521 & 6.3119 & 10.4828 & 11.0432 & 11.6247 & 14.1421 & 14.1421 & 14.4337 \\
\hline Second & 5.2852 & 5.8521 & 6.3372 & 13.7361 & 14.0028 & 14.433 & 15.6173 & 15.8114 & 16.0128 \\
\hline Third & 6.9843 & 7.6923 & 8.1923 & 10.6600 & 11.0432 & 11.6247 & 15.2498 & 15.3589 & 15.4303 \\
\hline Four & 7.4125 & 8.8761 & 9.0166 & 12.2169 & 12.5000 & 12.9099 & 16.0128 & 16.0128 & 16.0128 \\
\hline Five & 6.0971 & 6.8680 & 7.4743 & 11.9523 & 12.4035 & 13.0188 & 16.9031 & 16.9031 & 16.9031 \\
\hline
\end{tabular}

Table (5): The relation between the variations of natural frequencies with the stiffness of second steel spring (K2) in different cases.

\begin{tabular}{|c|c|c|c|c|c|c|c|c|c|}
\hline \multirow{2}{*}{ No of Case } & \multicolumn{3}{|c|}{ First natural frequency } & \multicolumn{3}{|c|}{ Second natural frequency } & \multicolumn{3}{|c|}{ Third natural frequency } \\
\hline & $\begin{array}{c}K_{2}= \\
12.0548\end{array}$ & $\begin{array}{c}K_{2}= \\
19.7609\end{array}$ & $\begin{array}{c}K_{2}= \\
28.3682\end{array}$ & $\begin{array}{c}K_{2}= \\
12.0548\end{array}$ & $\begin{array}{c}K_{2}= \\
19.7609\end{array}$ & $\begin{array}{c}K_{2}= \\
28.3682\end{array}$ & $\begin{array}{c}K_{2}= \\
12.0548\end{array}$ & $\begin{array}{c}K_{2}= \\
19.7609\end{array}$ & $\begin{array}{c}K_{2}= \\
28.3682\end{array}$ \\
\hline First & 5.7335 & 5.8521 & 5.9131 & 10.0000 & 11.0431 & 11.5470 & 13.4840 & 14.1421 & 15.4303 \\
\hline Second & 5.7354 & 5.8521 & 5.9235 & 12.5000 & 14.0028 & 15.2498 & 15.6174 & 15.8113 & 16.2221 \\
\hline Third & 7.6923 & 7.6923 & 7.6923 & 10.2062 & 11.0432 & 11.5470 & 14.4337 & 15.2498 & 16.4398 \\
\hline Four & 7.1611 & 8.2761 & 8.3045 & 11.8678 & 12.5000 & 13.3631 & 15.6173 & 16.0128 & 16.4031 \\
\hline Five & 6.8358 & 6.8681 & 6.8842 & 10.7211 & 12.4034 & 14.0028 & 16.9031 & 16.9031 & 17.1498 \\
\hline
\end{tabular}

Table (6): The relation between the variations of natural frequencies with the stiffness of third steel spring (K3) in different cases.

\begin{tabular}{|c|c|c|c|c|c|c|c|c|c|}
\hline \multirow{2}{*}{$\begin{array}{c}\text { No of } \\
\text { Case }\end{array}$} & \multicolumn{3}{|c|}{ First natural frequency } & \multicolumn{3}{c|}{ Second natural frequency } & \multicolumn{3}{c|}{ Third natural frequency } \\
\cline { 2 - 11 } & $\begin{array}{c}\mathbf{K}_{\mathbf{3}}= \\
\mathbf{1 2 . 0 5 4 8}\end{array}$ & $\begin{array}{c}\mathbf{K}_{\mathbf{3}}= \\
\mathbf{1 9 . 7 6 0 9}\end{array}$ & $\begin{array}{c}\mathbf{K}_{\mathbf{3}}= \\
\mathbf{2 8 . 3 6 8 2}\end{array}$ & $\begin{array}{c}\mathbf{K}_{\mathbf{3}}= \\
\mathbf{1 2 . 0 5 4 8}\end{array}$ & $\begin{array}{c}\mathbf{K}_{\mathbf{3}}= \\
\mathbf{1 9 . 7 6 0 9}\end{array}$ & $\begin{array}{c}\mathbf{K}_{\mathbf{3}}= \\
\mathbf{2 8 . 3 6 8 2}\end{array}$ & $\begin{array}{c}\mathbf{K}_{\mathbf{3}}= \\
\mathbf{1 2 . 0 5 4 8}\end{array}$ & $\begin{array}{c}\mathbf{K}_{\mathbf{3}}= \\
\mathbf{1 9 . 7 6 0 9}\end{array}$ & $\begin{array}{c}\mathbf{K}_{\mathbf{3}}= \\
\mathbf{2 8 . 3 6 8 2}\end{array}$ \\
\hline First & 5.0252 & 5.8521 & 6.3757 & 10.0504 & 11.0432 & 12.0386 & 12.7000 & 14.1421 & 15.8113 \\
\hline Second & 5.7259 & 5.8520 & 7.2547 & 12.9099 & 14.0028 & 14.4337 & 15.2498 & 15.8113 & 16.4398 \\
\hline Third & 7.6696 & 7.6696 & 7.6696 & 10.4257 & 11.0431 & 11.4707 & 14.1421 & 15.2498 & 16.6670 \\
\hline Four & 8.1378 & 8.2761 & 8.3918 & 12.4034 & 12.5000 & 12.9000 & 14.5865 & 16.0128 & 17.4077 \\
\hline Five & 6.337 & 6.8680 & 7.2547 & 12.4034 & 12.4055 & 12.5000 & 15.8113 & 15.2574 & 16.9031 \\
\hline
\end{tabular}


Table (7): The relation between the variations of natural frequencies with the stiffness of fourth steel spring (K4) in different cases.

\begin{tabular}{|c|c|c|c|c|c|c|c|c|c|}
\hline \multirow{2}{*}{$\begin{array}{c}\text { No of } \\
\text { Case }\end{array}$} & \multicolumn{3}{|c|}{ First natural frequency } & \multicolumn{2}{c|}{ Second natural frequency } & \multicolumn{2}{c|}{ Third natural frequency } \\
\cline { 2 - 10 } & $\begin{array}{c}\mathbf{K}_{4}= \\
\mathbf{1 2 . 0 5 4 8}\end{array}$ & $\begin{array}{c}\mathbf{K}_{\mathbf{4}}= \\
\mathbf{1 9 . 7 6 0 9}\end{array}$ & $\begin{array}{c}\mathbf{2 8 . 3 6 8 2} \\
\mathbf{2 8 . 3 6}\end{array}$ & $\begin{array}{c}\mathbf{K}_{\mathbf{4}}= \\
\mathbf{1 2 . 0 5 4 8}\end{array}$ & $\begin{array}{c}\mathbf{K}_{\mathbf{4}}= \\
\mathbf{1 9 . 7 6 0 9}\end{array}$ & $\begin{array}{c}\mathbf{K}_{\mathbf{4}}= \\
\mathbf{2 8 . 3 6 8 2}\end{array}$ & $\begin{array}{c}\mathbf{K}_{\mathbf{4}}= \\
\mathbf{1 2 . 0 5 4 8}\end{array}$ & $\begin{array}{c}\mathbf{K}_{\mathbf{4}}= \\
\mathbf{1 9 . 7 6 0 9}\end{array}$ & $\begin{array}{c}\mathbf{K}_{\mathbf{4}}= \\
\mathbf{2 8 . 3 6 8 2}\end{array}$ \\
\hline First & 5.3300 & 5.8925 & 6.2869 & 10.4828 & 11.0432 & 11.5470 & 13.8675 & 14.1421 & 14.5865 \\
\hline Second & 5.3149 & 5.8521 & 6.3119 & 13.8675 & 14.0028 & 14.1421 & 15.2498 & 15.8114 & 16.3498 \\
\hline Third & 7.1247 & 7.6923 & 8.0322 & 10.4828 & 11.0431 & 11.7041 & 15.0755 & 15.2498 & 15.4303 \\
\hline Four & 8.1378 & 8.2760 & 8.3918 & 11.9523 & 12.5000 & 12.9099 & 15.6173 & 16.0128 & 16.4398 \\
\hline Five & 6.7728 & 6.8680 & 6.9505 & 12.3091 & 12.4034 & 12.5000 & 16.2221 & 16.9031 & 17.6776 \\
\hline
\end{tabular}

Table (8): The relation between the variations of natural frequencies with the stiffness of fifth steel spring (K5) in different cases.

\begin{tabular}{|c|c|c|c|c|c|c|c|c|c|}
\hline \multirow{2}{*}{$\begin{array}{c}\text { No of } \\
\text { Case }\end{array}$} & \multicolumn{2}{|c|}{ First natural frequency } & \multicolumn{2}{c|}{ Second natural frequency } & \multicolumn{2}{c|}{ Third natural frequency } \\
\cline { 2 - 10 } & $\begin{array}{c}\mathbf{K}_{\mathbf{5}}= \\
\mathbf{1 2 . 0 5 4 8}\end{array}$ & $\begin{array}{c}\mathbf{K}_{\mathbf{5}}= \\
\mathbf{1 9 . 7 6 0 9}\end{array}$ & $\begin{array}{c}\mathbf{2 8 . 3 6 8 2} \\
\mathbf{N}_{\mathbf{5}}\end{array}$ & $\begin{array}{c}\mathbf{K}_{\mathbf{5}}= \\
\mathbf{1 2 . 0 5 4 8}\end{array}$ & $\begin{array}{c}\mathbf{K}_{\mathbf{5}}= \\
\mathbf{1 9 . 7 6 0 9}\end{array}$ & $\begin{array}{c}\mathbf{K}_{\mathbf{5}}= \\
\mathbf{2 8 . 3 6 8 2}\end{array}$ & $\begin{array}{c}\mathbf{K}_{\mathbf{5}}= \\
\mathbf{1 2 . 0 5 4 8}\end{array}$ & $\begin{array}{c}\mathbf{K}_{\mathbf{5}}= \\
\mathbf{1 9 . 7 6 0 9}\end{array}$ & $\begin{array}{c}\mathbf{K}_{\mathbf{5}}= \\
\mathbf{2 8 . 3 6 8 2}\end{array}$ \\
\hline First & 0 & 0 & 0 & 0 & 0 & 0 & 0 & 0 & 0 \\
\hline Second & 3.9013 & 5.8521 & 5.8521 & 13.7361 & 14.0028 & 14.1421 & 14.4337 & 15.8113 & 17.4077 \\
\hline Third & 7.1067 & 7.6923 & 8.1923 & 11.0432 & 11.0432 & 11.0432 & 14.7442 & 15.2498 & 15.8114 \\
\hline Four & 7.7382 & 8.2761 & 8.7370 & 12.3091 & 12.5000 & 12.7000 & 15.6174 & 16.0128 & 16.4398 \\
\hline Five & 6.7728 & 6.8680 & 6.9505 & 12.3091 & 12.4035 & 12.5000 & 16.2221 & 16.9031 & 17.6776 \\
\hline
\end{tabular}

Table (9): The relation between the variations of natural frequencies with the stiffness of sixth steel spring (K6) in different cases.

\begin{tabular}{|c|c|c|c|c|c|c|c|c|c|}
\hline \multirow{2}{*}{$\begin{array}{c}\text { No of } \\
\text { Case }\end{array}$} & \multicolumn{3}{|c|}{ First natural frequency } & \multicolumn{2}{c|}{ Second natural frequency } & \multicolumn{3}{c|}{ Third natural frequency } \\
\cline { 2 - 10 } & $\begin{array}{c}\mathbf{K}_{\mathbf{6}}= \\
\mathbf{1 2 . 0 5 4 8}\end{array}$ & $\begin{array}{c}\mathbf{K}_{\mathbf{6}}= \\
\mathbf{1 9 . 7 6 0 9}\end{array}$ & $\begin{array}{c}\mathbf{\mathbf { K } _ { \mathbf { 6 } } =} \\
\mathbf{2 8 . 3 6 8 2}\end{array}$ & $\begin{array}{c}\mathbf{K}_{\mathbf{6}}= \\
\mathbf{1 2 . 0 5 4 8}\end{array}$ & $\begin{array}{c}\mathbf{K}_{\mathbf{6}}= \\
\mathbf{1 9 . 7 6 0 9}\end{array}$ & $\begin{array}{c}\mathbf{K}_{\mathbf{6}}= \\
\mathbf{2 8 . 3 6 8 2}\end{array}$ & $\begin{array}{c}\mathbf{K}_{\mathbf{6}}= \\
\mathbf{1 2 . 0 5 4 8}\end{array}$ & $\begin{array}{c}\mathbf{K}_{\mathbf{6}}= \\
\mathbf{1 9 . 7 6 0 9}\end{array}$ & $\begin{array}{c}\mathbf{K}_{\mathbf{6}}= \\
\mathbf{2 8 . 3 6 8 2}\end{array}$ \\
\hline First & 0 & 0 & 0 & 0 & 0 & 0 & 0 & 0 & 0 \\
\hline Second & 5.8521 & 5.8521 & 5.8521 & 14.0028 & 14.0028 & 14.0028 & 15.8113 & 15.8113 & 15.8113 \\
\hline Third & 7.6923 & 7.6923 & 7.6923 & 11.0432 & 11.0432 & 11.0432 & 15.2498 & 15.2498 & 15.2498 \\
\hline Four & 8.1378 & 8.2761 & 8.3918 & 11.9523 & 12.5000 & 12.9099 & 15.6174 & 16.0128 & 16.4398 \\
\hline Five & 6.7728 & 6.8680 & 6.9504 & 12.3091 & 12.4035 & 12.5000 & 16.2221 & 16.9031 & 17.6776 \\
\hline
\end{tabular}

\section{REFERENCES}

W. Rączka, J. Konieczny, and M. Sibielak, "Mathematical Model of a Shape Memory Alloy Spring Intended for Vibration Reduction Systems,” vol. 177, no. 1, pp. 65-75, 2011.

Y. Han, Q. S. Li, A. Li, A. Y. T. Leung, and P. Lin, "Structural vibration control by shape memory alloy damper," Journal of Mechanical Engineering; Southeast University vol. 494, no. August 2002, pp. 483-494, 2003. 
G. Sung, N. Ma, and H. Li, "Applications of shape memory alloys in civil structures," Journal of Engineering Structures vol. 28, pp. 1266-1274, 2006.

Barbara Tiseo, Antonio Concilio, and Salvatore Ameduri "A Shape Memory Alloys Based Tunable Dynamic Vibration Absorber for Vibration Tonal Control" , Journal of theoretical and applied mechanics, Vol. 48, No. 1, pp. 135-153, Warsaw 2010.

M. Bendame, "Mathematical Modeling and Control of Nonlinear Oscillators with Shape Memory Alloys", Journal of Wilfrid Laurier Universit 2010.

S.A. Chavan, "Analytical and Experimental Analysis of Composite Beam by Using Shape Memory Alloy Wires", International Journal of Emerging Technology and Advanced Engineering, Volume 4, Issue 7, July 2014.

M. Elahinia, "Improving robustness of tuned vibration absorbers using shape memory alloys," Journal of Shock and Vibration, no. 5, pp. 349-361, 2015.

F. Zdraveski and E. Donceva, "ANNALS of Faculty Engineering Hunedoara - International Journal of Engineering," vol. 2, pp. 31-36, 2016.

N. Wagner, I. G. Stuttgart, R. Helfrich, and I. G. Stuttgart, "Dynamic Vibration Absorbers and its Applications," Journal of Sound and Vibration, Vol. 354, No. June, pp. 6, 2017.

F.A.D.Santos, and J.Nunes, "Toward an adaptive vibration absorber using shape-memory alloys , for civil engineering applications" , Journal of Intelligent Material Systems and Structures,pp,729-740, 2018.

L. Rebenfeld, "Chapter Vifibers and Fibrousmateriats TRI / Princeton , P . O . Box 625, Princeton , New Jersey 08542 , USA,” pp. 199-232, 2002.

Product Data Sheet, Kellogg's Research 